\title{
Advantages and Disadvantages of Telecommuting: An Observation
}

\author{
Dilip Parajuli, Ph.D. \\ Associate Professor, Bhaktapur Multiple Campus, T.U.
}

\begin{abstract}
This paper aims to explore the advantages and disadvantages of telecommuting. In particular, the research design for the study is descriptive. A basic research tool used to gather data on the advantages and disadvantages of telecommuting is the questionnaire survey. The questionnaire was sent to 73 faculties of the three constituent campuses of Tribhuvan University. Based on the results, it is found that flexible working hours are the key advantage of telecommuting in the teaching field. The second key advantage is an improvement in time management. The third advantage is savings in travel time and expenses. The least advantage of telecommuting is professional flexibility. It is also found that feeling of isolation is one of the key disadvantages of telecommuting. The second key disadvantage is no separation between spheres of work and home that is followed by overavailability syndrome, ditched society, investment in training, and personality unsuitability. The least disadvantage of telecommuting is the lack of professional support. By avoiding such types of disadvantages, our organizations can get many benefits by adapting telecommuting as the few and flexible work methods.
\end{abstract}

Keywords: Telecommuting, Advantages, Disadvantages, e-work, Flexible work method

\section{Introduction}

Working from home is becoming common everywhere. It is not a new phenomenon (Harpaz, 2002). Traditionally, most of the works are carried out at the office and it is still common in our context. However, the advent of modern communication technology especially information technology (IT) has created an environment of working far away from the office. Such an environment offers the opportunities of working from anywhere that is known as telecommuting.

Telecommuting is the method of working for an organization from home and communicating by using a personal computer fitted with a modem and applications for communication. It is a method used by more and more companies and workers, especially in today's age, where a large number of companies operate entirely from home (www.aib.edu.au/blog/culture/telecommuting/pros-and-cons-of-organizations/). Cooper (1996) stated that the use of electronic communications as the primary medium of interaction between the e-work performed and the employing organization is telecommuting.

Belanger (1999) reported that the availability of inexpensive and rapid computers, speedy and reliable communication lines, Internet expansion, and the ability to move files around and work on files from offlocation stations are some of the key aspects of technological developments that have made telecommuting easy, accessible and relatively inexpensive. Telecommuting removes the location and time constraints and allows a return to home-based working. It is no longer imperative to travel to and from the organization daily (Harpaz, 2002). It is a popular option for many workers in this intensely technical age. In recent 
circumstances, the concept of telecommuting is getting popular in the Nepalese context too. Thus, this study aims to examine the advantages and disadvantages of telecommuting in the Nepalese context.

\section{Review of Literature}

The practice of telecommuting has become an increasingly popular working method. Allen, Golden, and Shockley (2015) claim that working away from the workplace as a telecommuter has become more and more accessible to many workers around the world with recent technological advances that make mobile access at ever-affordable rates. Telecommuting is the act of operating through computer-based technologies away from the conventional workplace while maintaining contact with it (Bailey, Kurland, \& Kurland, 2002). Most previous sources of literature have shed light on telecommuting activities at workplaces. Harpaz (2002) announced that a modern flexible work arrangement is telecommuting. E-work, the method of working from a distance from home, is often called e-work. The individuals who are also regarded as telecommuters operate at home, but within an organizational system structure. Cooper (1996) argues that telecommuters can structure their work tasks and working life in many ways based on the nature of the work, the organization, the customer-based, etc.

In case of advantages and disadvantages of telecommuting practices, many previous studies (e.g., Baruch, 2000; Jurik, 1998; Bussing, 1998; Perin, 1991; Pratt, 1993; Hesse \& Grantham, 1991; Belanger, 1999; Allen, Johnson, Kiburz, \& Shockley, 2013; Bélanger, Watson-Manheim, \& Swan, 2013; Fay \& Kline, 2012; Golden \& Veiga, 2005; Allen et al., 2015, Golden, 2006; Kossek, Lautsch, \& Eaton, 2006; Pearce, 2009; Shabanpour, Golshani, Tayarani, Auld, \& Mohammadian, 2018; de Vries, Tummers \& Bekkers, 2019)have presented their results. Going through the conclusions of these studies some of the advantages of telecommuting for individuals can be autonomy/independence, flexible working hours, improvement in time management, professional flexibility, and savings in travel time and expenses, flexibility in arranging supervision of family members/dependents. Likewise, some of the advantages of telecommuting for organizations are increased productivity, increased provision of human resources, a significant decrease in absence and tardiness levels, savings in direct expenses, increased motivation and satisfaction, creation of a positive organizational image, etc. Besides, some of the advantages of telecommuting for society are reduction of environmental damage, decrease in traffic/congestion, solutions for special-needs populations, savings in infrastructure and energy. However, there are some disadvantages of telecommuting. Some of them are impaired feeling of belonging, feeling of isolation, no separation between spheres of work and home, need for self-discipline, lack of professional support, impeded career advancement, over-availability syndrome, personality unsuitability, legal issues, application difficulties for organizations with centralized management, investment in training and new supervision methods, possible damage to a commitment to, and identification with, the organization, changes in work methods, cost involved in the transition to telecommuting, creation of detached society, etc.

\section{Research Methods}

In particular, the research design for the study is descriptive. A basic research tool used to gather data on the advantages and disadvantages of telecommuting is the questionnaire survey. The questionnaire was approached to 73 faculties of three constituent campuses (namely, Padma Kanya Multiple Campus, Patan Multiple Campus, and Shankar Dev Campus). These faculties have given their perception regarding some of the advantages and disadvantages of telecommuting.. The detail of respondents is depicted in Table 1. 
Table 1

Respondents' Profile

\begin{tabular}{lcc}
\hline & Number of Respondents & Percentage \\
\hline Gender & 44 & \\
Male & 29 & 60.27 \\
Female & & 39.73 \\
Age & 2 & \\
Below 30 year & 51 & 2.74 \\
$31-40$ year & 17 & 69.86 \\
$41-50$ year & 3 & 23.29 \\
Above 50 years & & 4.11 \\
Job Status & 29 & \\
Permanent & 32 & 39.73 \\
Teaching Assistants & 12 & 43.84 \\
Part-time & & 16.44 \\
\hline
\end{tabular}

As shown in the above table, the majority of respondents (60.27\%) are male, $69.86 \%$ are age group of 31-40 years, and 43.84 are teaching assistants.

\section{Data Analysis and Results}

The following section describes the items under advantages of telecommuting.

Table2:

Advantages of telecommuting

\begin{tabular}{llccc}
\hline S.N. & Indicators & Response & Percentage & Rank \\
\hline 1. & Flexible working hours & 71 & 97.26 & 1 \\
2. & Autonomy/independence & 41 & 56.16 & 7 \\
3. & Improvement in time management & 67 & 91.78 & 2 \\
4. & Professional flexibility & 25 & 34.25 & 8 \\
5. & Savings in travel time and expense & 60 & 82.19 & 3 \\
6. & Flexibility in family matters & 55 & 75.34 & 5 \\
7. & Increased motivation and satisfaction & 59 & 80.82 & 4 \\
8. & Savings in direct expenses & 45 & 61.64 & 6 \\
\hline
\end{tabular}

Source: Survey (2019).

Table 2 presents the key advantages of telecommuting. The results show that the majority of the respondents $(97.26 \%)$ believe that telecommuting provides flexible working hours. $91.78 \%$ of respondents believe that telecommuting provides an improvement in time management. $82.19 \%$ of respondents believe that telecommuting provides savings in travel time and expense. $80.82 \%$ of respondents believe that telecommuting provides motivation and satisfaction. Further, $75.34 \%$ of respondents believe that telecommuting provides flexibility in family matters. Besides, $61.64 \%$ of respondents believe that telecommuting provides savings in direct expenses. Moreover, $56.16 \%$ of respondents believe that telecommuting provides autonomy and independence at work. Finally, only a few of the respondents (34.25\%) believe that telecommuting provides professional flexibility.

The following section describes the items under disadvantages of telecommuting. 
Table 3:

Disadvantages of telecommuting

\begin{tabular}{lllll}
\hline S.N. & Indicators & Response & Percentage & Rank \\
\hline 1. & Feeling of isolation & 72 & 98.63 & 1 \\
2. & No separation between spheres of work and home & 71 & 97.26 & 2 \\
3. & Need for self-discipline & 68 & 93.15 & 5 \\
4. & Lack of professional support & 54 & 73.97 & 8 \\
5. & Over-availability syndrome & 70 & 95.89 & 3 \\
6. & Personality unsuitability & 59 & 80.82 & 7 \\
7. & Investment in training & 64 & 87.67 & 6 \\
8. & Creation of detached society & 69 & 94.52 & 4 \\
\hline
\end{tabular}

Source: Survey (2019).

Table 3 presents some of the disadvantages of telecommuting. The results explain that the majority of the respondents $(98.63 \%)$ agree that telecommuting causes a feeling of isolation. $97.26 \%$ of respondents agree that telecommuting causes no separation between spheres of work and home. $95.89 \%$ of respondents agree that telecommuting causes over-availability syndrome. $94.52 \%$ of respondents agree that telecommuting creates a ditched society. $93.15 \%$ of respondents believe that telecommuting causes to need for self-discipline. Further, $87.67 \%$ of respondents agree that telecommuting leads to investment in training. Besides, $80.82 \%$ of respondents believe that telecommuting leads to personality unsuitability. Finally, $73.97 \%$ of respondents agree that telecommuting causes to lack of professional support.

\section{Conclusion}

Based on the results, it is found that flexible working hours are the key advantage of telecommuting in the teaching field. It indicates that a workstation at home allows work activity to take place at any time of the day or night, increased by more efficient use of technological equipment, planning of leisure time, and a balancing of other tasks that individuals fulfill in the domains of family and community. The second key advantage is an improvement in time management. It indicates that telecommuting allows the possibility of working with less exposure to distractions. The third advantage is savings in travel time and expenses. It indicates that due to telecommuting people need not waste long and stressful hours stuck in traffic on journeys to and from work. The least advantage of telecommuting is professional flexibility. It indicates that telecommuting allows people to work in their desired professions.

It is also found that feeling of isolation is one of the key disadvantages of telecommuting. It indicates that due to telecommuting people miss talking to other people or sharing their achievements with them. The second key disadvantage is no separation between spheres of work and home that is followed by overavailability syndrome, ditched society, investment in training, and personality unsuitability. It indicates that due to telecommuting people cannot be able to transform home-related aspects to work issues. Likewise, they need to work at any time; they also need to spend money on training activities. Besides, various personal qualities make telecommuting difficult. The least disadvantage of telecommuting is the lack of professional support. It indicates that if people need professional support at work, telecommuting does provide such support. Finally, it can be concluded that by avoiding such types of disadvantages, our organizations can get many benefits by adapting telecommuting as the few and flexible work methods.

\section{References}

Allen, T. D., Johnson, R. C., Kiburz, K., \& Shockley, K. M. (2013). Work-family conflict and flexible work arrangements: Deconstructing flexibility. Personnel Psychology, 66, 345-376.

Allen, T.D., Golden, T.D., \& Shockley, K.M. (2015). How Effective Is Telecommuting? Assessing the 
Status of Our Scientific Findings. Psychological Science in the Public Interest, 16(2) 40-68.

Bailey, D.E., Kurland, N.B., \& Kurland, N.B. (2002). A Review of Telework Research: Findings, New Directions, and Lessons for the Study of Modern Work. Journal of Organizational Behavior, 23(4), 383-400.

Baruch, Y. (2000). Teleworking: benefits and pitfalls as perceived by professionals and managers. Work and Employment, 15, 34-49.

Belanger, F. (1999). Workers' propensity to telecommute: and empirical study. Information and Management $35,139-153$.

Bélanger, F., Watson-Manheim, M. B., \& Swan, B. R. (2013). A multi-level socio-technical systems telecommuting framework. Behaviour \& Information Technology, 32, 1257-1279.

Bussing, A. (1998). Teleworking and quality of life. In Jackson, P.J. and Vand Der Wielen, J.M (Eds). Teleworking: International Perspective. Routledge, London.

Cooper R.C. (1996). Telecommuting: the good, the bad and the particulars. Supervision, 57, 10-12.

de Vries, H., Tummers, L., \& Bekkers, V. (2019). The benefits of teleworking in the public sector: reality or rhetoric? Review of Public Personnel Administration, 39(4) 570-593.

Fay, M. J., \& Kline, S. L. (2012). The influence of informal communication on organizational identification and commitment in the context of high-intensity telecommuting. Southern Communication Journal, $77,61-76$.

Golden, T. D. (2006). The role of relationships in understanding telecommuter satisfaction. Journal of Organizational Behavior, 27, 319-340.

Golden, T. D., \& Veiga, J. (2005). The impact of extent of telecommuting on job satisfaction: Resolving inconsistent findings. Journal of Management, 31, 301-318.

Harpaz, I. (2002). Advantages and disadvantages of telecommuting for the individual, organization and society. Work Study: A Journal of Productivity Science, 51, 74-80.

Hesse, B., \& Grantham, C.E. (1991). Electronically distributed work communities: implications for research on telework. Electronic Networking: Research Application and Policy, 1, 4-17.

Jurik, N. (1998). Getting away and getting by: the experience of self-employed homeworkers. Work and Occupations, 25, 7-35.

Kossek, E. E., Lautsch, B. A., \& Eaton, S. C. (2006). Telecommuting, control, and boundary management: Correlates of policy use and practice, job control, and work-family effectiveness. Journal of Vocational Behavior, 68, 347-367.

Pearce, J. (2009). Successful corporate telecommuting with technology considerations for late adopters. Organizational Dynamics, 38, 16-25.

Perin, C. (1991). The moral fabric of the office: panoptical discourse and schedule flexibilities. Research in the Sociology of Organizations, 8, 241-268.

Pratt, J.H. (1993). Myths and realities of working at home: Characteristic of home-based business owners and telecommuters. National Information Technical Service, Springfield, V.A.

Shabanpour, R., Golshani, N., Tayarani, M., Auld, J., \& Mohammadian,A. (2018) Analysis of Telecommuting and Impacts on Travel Demand and the Environment. Transportation Research Part D: Transport and Environment, 62, 563-576.

www.aib.edu.au/blog/organisations-culture/the-pros-and-cons-of-telecommuting/ 
Issue 1 May/June 2020 - 